\title{
INFLUÊNCIA DA FILTRAÇÃO NO PROCESSO DE CONCENTRAÇÃO DA VINHAÇA
}

\author{
J. O. ALVES ${ }^{1}$, F. O. QUEIROZ ${ }^{2}$, D. C. FERREIRA ${ }^{1}$ e M. B. SILVA ${ }^{2}$ \\ ${ }^{1}$ Universidade Federal do Triângulo Mineiro, Departamento de Engenharia Química \\ ${ }^{2}$ Universidade Federal do Triângulo Mineiro, PMPIT \\ E-mail para contato: bacciuftm@gmail.com
}

\begin{abstract}
RESUMO - O setor sucroalcooleiro é caracterizado pela alta demanda de água e no contexto da sustentabilidade e uso racional de recursos hídricos, devido à escassez, surgiram novas tecnologias de reaproveitamento da água gerada pela etapa de evaporação da vinhaça. O objetivo deste trabalho foi estudar a evaporação de vinhaça, propondo uma filtração simples em escala laboratorial de amostras de vinhaça de uma usina sucroalcooleira, visando reduzir o consumo energético na etapa de evaporação. Como resultado, verificou-se que a etapa de filtração da vinhaça não alterou de maneira significativa as propriedades da água de reuso, entretanto foi notória uma maior concentração dos sólidos na vinhaça filtrada, com maior elevação dos graus brix e, consequentemente, maior geração de água para reuso. Pode-se afirmar que existe a viabilidade do reuso da água a partir da concentração da vinhaça, podendo utilizá-la com fins menos nobres, reduzindo a captação na fonte.
\end{abstract}

\section{INTRODUÇÃO}

Tendo em vista os cenários político, econômico e social, aliados a crescente demanda energética no país, faz-se necessário a busca por alternativas visando a sustentabilidade e o uso racional dos recursos hídricos. Baseado no contexto de sustentabilidade foi criado o Programa Nacional do Álcool (Proálcool), onde o álcool combustível ou etanol substituiria a gasolina, sendo este menos agressivo ao meio ambiente (AMORIM \& LEÃO, 2005).

Para a produção do etanol a partir da cana-de-açúcar há um consumo elevado de água e formação de um subproduto conhecido como vinhaça. O consumo de água em 2005 foi de 1,8 $\mathrm{m}^{3}$ de cana-de-açúcar (CARVALHO, 2010). A Secretaria do Meio Ambiente, através do decreto SMA-88 de 19 de dezembro de 2008, determina que, para novas usinas, o consumo deva ser de $0,7 \mathrm{~m}^{3}$ por tonelada de cana-de-açúcar processada (SILVA et al, 2011).

Devido a grande demanda dos recursos hídricos, o setor sucroalcooleiro percebeu a necessidade da utilização de outras fontes garantindo a segurança dos corpos d'água da indústria canavieira, através do reaproveitamento hídrico da vinhaça.

Sendo assim, este trabalho possui como propósito estudar o processo de evaporação da vinhaça in natura e filtrada, em escala laboratorial, comparando os resultados físico-químicos encontrados e avaliando o consumo energético de evaporação nas duas situações. 


\section{MATERIAIS E MÉTODOS}

O presente trabalho foi desenvolvido utilizando amostras de vinhaça coletadas na destilaria de uma usina de açúcar e etanol, localizada no município de Uberaba-MG. Foram coletadas por amostra aproximadamente 3 litros de vinhaça, entre os meses de outubro e novembro de 2016. A amostra foi armazenada em frasco plástico, colocada em caixa térmica e transportada para o local de realização das análises físico-químicas e ensaio de evaporação.

A parte experimental do trabalho foi desenvolvida no laboratório da usina, envolvendo a aplicação de técnicas analíticas para análise de $\mathrm{pH}$, porcentagem de sólidos solúveis e dissolvidos, ${ }^{\circ}$ Brix e condutividade. Os ensaios de filtração e evaporação foram realizados no Laboratório de Análises Físico-Químicas da UFTM. Todas as análises foram realizadas em triplicatas.

\subsection{Determinação De Sólidos}

Sabe-se que, sólido é o estado da matéria caracterizado pela rigidez, por uma forma própria e pela existência de um equilíbrio com o líquido proveniente de uma fusão. Assim, pode-se definir que toda substância que permaneça com essas características na vinhaça, mesmo após operações de secagem e calcinação, é denominada sólido.

As tréplicas do experimento de análise dos sólidos em suspensão e dissolvidos ocorreram com filtração e evaporação de aproximadamente $0,140 \mathrm{~L}$ de amostra de vinhaça em um cadinho previamente seco a uma temperatura de $378 \mathrm{~K}$ e pesado, até seu peso constante.

A amostra de vinhaça foi filtrada à vácuo em filtro seco e pesada previamente, com poro de diâmetro $\leq 1,2 \mu \mathrm{m}$, antes da evaporação. Neste caso, o material retido no filtro foi seco a $378 \mathrm{~K}$ em estufa, enquanto o material filtrado foi evaporado usando bico de Bunsen e seco a 453K também em estufa, para determinar os sólidos em suspensão e os sólidos dissolvidos, respectivamente.

\subsection{Energia Necessária Para Evaporar A Vinhaça}

Um multímetro foi empregado para determinação da potência real do ebulidor elétrico utilizado para a concentração da vinhaça. Aferindo-se a corrente elétrica fornecida pela rede elétrica e ligando-se o multímetro em série com o ebulidor em funcionamento, tem-se o valor exato da potência. Usando o tempo gasto tem-se a energia necessária para evaporar a vinhaça.

\subsection{Filtração Da Vinhaça}

Foi estruturado um sistema de filtração simples, filtrando $1 \mathrm{~L}$ da amostra, coletado em um béquer de 1L. A estrutura foi composta por um único filtro com um elemento filtrante, uma malha de nylon com 200 mesh $(0,074 \mathrm{~mm})$ de abertura, colocado em um funil preso por uma argola. 


\subsection{Evaporação Da Vinhaça}

Para evaporação da amostra de 1L, foi utilizado um ebulidor elétrico durante 30 minutos. Após a solução atingir a temperatura de $363 \mathrm{~K}$, uma alíquota de $10 \mathrm{~mL}$ era coletada a cada 5 minutos e armazenada em recipiente hermeticamente fechado e rotulado. A leitura do ${ }^{\circ}$ Brix foi feita através de refratômetro digital, marca DIGIMED modelo DM-22, num total de doze amostras, sendo seis de vinhaça evaporada in natura e seis de vinhaça evaporada filtrada.

\section{RESULTADOS}

\subsection{Análise Físico-Química Da Vinhaça}

Para estabelecer os parâmetros significativos na análise da vinhaça, optou-se por analisar o $\mathrm{pH},{ }^{\circ}$ Brix e os sólidos totais. A Tabela 1 apresenta os resultados dos parâmetros analisados para as amostras de vinhaça coletadas e realizados em triplicata.

Tabela 1 - leitura do $\mathrm{pH}$ e ${ }^{\circ}$ Brix das amostras

\begin{tabular}{|c|c|c|}
\hline Amostra & ${ }^{\circ}$ Brix & $\mathrm{pH}$ \\
\hline \hline I & 3,30 & 4,72 \\
\hline II & 2,09 & 4,67 \\
\hline III & 2,90 & 4,67 \\
\hline média & $2,76 \pm 0,63$ & $4,68 \pm 0,03$ \\
\hline
\end{tabular}

Os valores dos parâmetros da Tabela 1 foram semelhantes aos resultados de ${ }^{\circ}$ Brix encontrados por Carvalho (2010) e do pH por Paula (2010), validando o método experimental das medições efetuadas no trabalho.

A utilização da etapa de evaporação para reduzir a quantidade de material volátil e assim obter um produto mais concentrado, provoca um aumento do ${ }^{\circ}$ Brix da vinhaça in natura, como pode ser observado na Figura 1 a seguir. Consequentemente há redução de seu volume, possibilitando a reutilização do material mais volátil, neste caso a água.

Figura 1 - Analise do ${ }^{\circ}$ Brix durante a evaporação

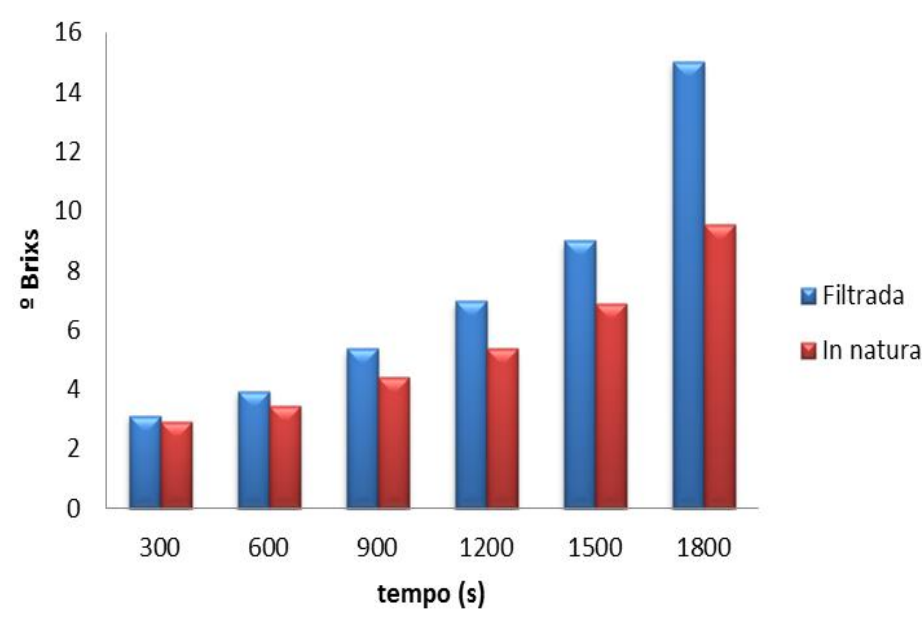


A Figura 1 mostra o comportamento do ${ }^{\circ}$ Brix ao longo do tempo, em que a vinhaça foi submetida à evaporação. Nota-se que a vinhaça filtrada após a evaporação se apresenta mais concentrada, pois sua solução encontra-se livre de partículas em suspensão, as quais atrapalhariam a troca térmica, e, por conseguinte, o processo de evaporação. Assim, a quantidade de água para o reuso obtida foi maior, reduzindo a captação nos corpos d'água.

Houve uma redução do volume de vinhaça que foi sucumbida a filtração simples, diminuindo a quantidade de vinhaça que seria utilizada nas lavouras de cana de açúcar, causando um menor consumo energético.

A Tabela 2 apresenta os valores quantificados para os sólidos que ficaram retidos no filtro durante o processo de filtração e os que permaneceram no filtrado da vinhaça, respectivamente. Verifica-se que o filtro conseguiu reter em média 2,5g de sólidos da amostra, os quais poderão ser adicionados a outros fertilizantes organominerais provenientes da planta industrial e posterior aplicação nas lavouras de cana de açúcar. Como já era esperado, o processo de filtração não reteve todos os sólidos em sua totalidade. Cerca de $2 \mathrm{~g}$ de sólidos permaneceram no filtrado, provavelmente composta por sais, açúcares infermentescíveis e outros produtos misturados ao mosto de caldo de cana utilizado para a produção de etanol, que resultaram na composição da vinhaça.

Tabela 2 - Quantidade de sólidos retidos no filtro e sólidos no filtrado

\begin{tabular}{|c|c|c|}
\hline Amostra & $\begin{array}{c}\text { Sólidos retidos } \\
(\mathrm{g})\end{array}$ & $\begin{array}{c}\text { Sólidos no } \\
\text { filtrado }(\mathrm{g})\end{array}$ \\
\hline $\mathrm{I}$ & $2,34 \pm 0,20$ & $2,19 \pm 0,05$ \\
\hline II & $2,73 \pm 0,20$ & $2,06 \pm 0,05$ \\
\hline III & $2,49 \pm 0,20$ & $2,11 \pm 0,05$ \\
\hline Média & $2,49 \pm 0,20$ & $2,12 \pm 0,05$ \\
\hline
\end{tabular}

De acordo com CTC (2008), conforme citado por Paula (2011), estudos sobre a utilização da vinhaça em lavadores de gazes de caldeiras de usinas sucroalcooleiras relatam que a composição da vinhaça de cana de açúcar possuí, em média, $18420 \mathrm{mg} / \mathrm{L}$ de sólidos dissolvidos totais (SDT) em amostras de usinas do estado de São Paulo. Neste trabalho foram encontrados aproximadamente $16000 \mathrm{mg} / \mathrm{L}$ em média das amostras analisadas, conforme apresentado na Tabela 3. Comparando os resultados encontrados pelo CTC (2008) a respeito dos sólidos solúveis totais $(9500 \mathrm{mg} / \mathrm{L})$ pode se dizer que o presente trabalho encontrou um resultado maior $(11410 \mathrm{mg} / \mathrm{L})$.

Tabela 3 - Quantidade de sólidos em suspensão total e sólidos dissolvidos totais

\begin{tabular}{|c|c|c|}
\hline Amostra & SST $(\mathrm{mg} / \mathrm{L})$ & SDT $(\mathrm{mg} / \mathrm{L})$ \\
\hline \hline I & $10381,89 \pm 1299,51$ & $16534,73 \pm 511,15$ \\
\hline II & $13218,76 \pm 1299,51$ & $15522,71 \pm 511,15$ \\
\hline III & $10630,14 \pm 1299,51$ & $15390,28 \pm 511,15$ \\
\hline Média & $11410,63 \pm 1299,51$ & $15815 \pm 511,15$ \\
\hline
\end{tabular}




\subsection{Energia Necessária Para Evaporar A Vinhaça}

Para análise da energia gasta ao evaporar a vinhaça, esperava-se um mesmo consumo de energia, mas desempenhos diferentes para a vinhaça filtrada em relação à vinhaça in natura foram observados. Através da leitura de tensão da rede elétrica e da corrente feitas por um multímetro, calculou-se a energia consumida durante o experimento e os resultados são apresentados na Tabela 4:

Tabela 4- Energia consumida durante a evaporação da vinhaça

\begin{tabular}{|c|c|c|c|}
\hline Tempo (s) & $\begin{array}{c}\text { 'Brix médio da } \\
\text { vinhaça filtrada } \\
(\%)\end{array}$ & $\begin{array}{c}{ }^{\circ} \text { Brix médio da } \\
\text { vinhaça in } \\
\text { natura }(\%)\end{array}$ & $\begin{array}{c}\text { Energia } \\
\text { consumida (J) }\end{array}$ \\
\hline \hline 300 & 3,12 & 2,92 & 308945,4 \\
\hline 600 & 3,94 & 3,46 & 617890,8 \\
\hline 900 & 5,36 & 4,42 & 926836,2 \\
\hline 1200 & 6,96 & 5,36 & 1235781,6 \\
\hline 1500 & 9,01 & 6,9 & 1544727,0 \\
\hline 1800 & 15,03 & 9,53 & 1853672,4 \\
\hline
\end{tabular}

Como foi mostrado na tabela anterior, o consumo energético mostrou-se o mesmo, já a concentração em ${ }^{\circ}$ Brix da vinhaça filtrada apresentou valores mais elevados, tendo melhor desempenho em relação à vinhaça in natura devido ao seu volume de matéria orgânica reduzida e quantidade de água de reuso gerada.

\subsection{Análise Físico-Química Da Água De Reuso}

A Tabela 5 destaca os resultados encontrados da água recuperada das amostras submetidas ao processo de evaporação e os valores desejados oriundos da captação (água bruta ou industrial), podendo compará-los. A filtração da vinhaça não alterou a qualidade da água de reuso quanto aos parâmetros analisados quando comparados à água de reuso da vinhaça in natura.

Tabela 5 - Resultados analíticos da água de reuso

\begin{tabular}{|c|c|c|c|}
\hline Parâmetro & Água da vinhaça filtrada & Água da vinhaça in natura & Limites desejados \\
\hline $\mathrm{pH}$ & $4,50 \pm 0,01$ & $4,50 \pm 0,01$ & $6,8-8,0$ \\
\hline Turbidez (NTU) & $1,95 \pm 0,32$ & $1,81 \pm 0,24$ & Max 20,0 \\
\hline Dureza Total (ppm) & $75,00 \pm 0,78$ & $70,00 \pm 0,60$ & Max 40,0 \\
\hline Dureza cálcica (ppm) & $49,00 \pm 0,28$ & $50,00 \pm 0,29$ & Max 30,0 \\
\hline $\begin{array}{c}\text { Dureza magnesiana } \\
(\mathrm{ppm})\end{array}$ & $26,00 \pm 0,50$ & $20,00 \pm 0,42$ & - \\
\hline Alcalinidade total (ppm) & $44,00 \pm 0,40$ & $45,00 \pm 0,36$ & Max 60 \\
\hline
\end{tabular}


Devido a acidez da vinhaça, o $\mathrm{pH}$ da água de reuso apresentou a mesma característica. Assim, recomenda-se ajustar o $\mathrm{pH}$ para o limite desejado, evitando corrosão ou outros danos aos equipamentos ou às tubulações da planta industrial.

A turbidez da água é um parâmetro operacional muito importante para o controle das etapas de coagulação-floculação, sedimentação e filtração (MOUNTEER, 2008). O resultado obtido permite afirmar que, não seria necessário aplicar nenhum tipo de tratamento para a remoção da turbidez na água de reuso.

\section{CONCLUSÃO}

Dessa forma, as etapas de filtração e evaporação da vinhaça foram realizadas, a fim de analisar as propriedades físico-químicas da água coletada. Foi observado que a etapa de filtração da vinhaça não alterou significativamente as propriedades da água de reuso, no entanto, foi verificada, após a etapa de evaporação, uma maior concentração dos sólidos solúveis, na vinhaça filtrada, mostrando que, a filtração simples da vinhaça acarreta maior elevação do ${ }^{\circ}$ Brix e consequentemente maior coleta de água para reuso.

Atendendo aos conceitos de sustentabilidade e inovação, o trabalho mostrou-se viável quanto ao reuso da água a partir do processo de concentração da vinhaça, já que o consumo energético não foi alterado. Assim, a água coletada pode ser utilizada para fins menos nobres, por exemplo, limpeza geral e reposição de água em torres de resfriamento.

Enfim, o desenvolvimento sustentável e inovador da indústria sucroalcooleira deve ser baseado em economia, sociedade e meio ambiente, atendendo dessa maneira, a demanda de água, onde os efluentes devem ser usados como ferramenta para a proteção das fontes, aumentando a eficiência e reduzindo sua captação.

AGRADECIMENTO: Os autores agradecem o apoio financeiro provido pela FAPEMIG (PCE00455-17: Participação Coletiva em Eventos Técnico-Científicos).

\section{REFERÊNCIAS}

AMORIM, H. V.; LEÃO, R. M. Fermentação alcoólica: ciência e tecnologia. Piracicaba: Fermentec, 2005.

CARVALHO, T.C. Redução do volume de vinhaça pelo processo de evaporação. Dissertação (mestrado)- Faculdade de Engenharia da UNESP -Bauru, 2010.

MOUNTEER, A. H; NASCIMENTO, L.E; BASTOS, R.K.X. CIV-442 Qualidade da água. Apostila de aulas práticas. UFV-Centro de Ciências Exatas e Tecnológicas - Departamento de Engenharia Civil. Viçosa, 2008.

PAULA, N.A. Avaliação da utilização de vinhaça como líquido em lavadores de gases. Dissertação (mestrado) - UNAERP - Ribeirão Preto, SP, 2011.

SILVA, F. C.; CESAR, M. A. A.; MORAES, J.; VILELA, M.; MENDES, C. Diagnóstico hídrico em destilarias de álcool em São Paulo. Bioenergia em Revista: Diálogos, Piracicaba, jan./jun, 2011. 